Health care

\section{Health services: who are the best advocates for children?}

\section{E Webb}

"Advocacy is not about saying what's best for a child or young person but about enabling that child or young person to come to informed decisions about matters which are affecting their lives"

T his quotation comes from the evidence given by the Children's Society in Wales to the Carlisle review into safeguards for children and young people treated and cared for by the NHS in Wales. This usage of the term is now commonplace in local authorities and voluntary agencies, in which advocacy is a process firmly focused at an individual level. It is at odds with the definitions provided in the Oxford English Dictionary:

- Advocacy: "the function of an advocate".

- Advocate: "one who pleads, intercedes, or speaks for another".

This shift in usage leads is not only confusing, but devalues the process of speaking on behalf of others. For the purposes of this paper I will stick to the Oxford English Dictionary definition of advocacy and use the somewhat unsatisfactory term of "self advocacy" to describe the process by which individuals or groups are supported and empowered to speak for themselves.

\section{SELF ADVOCACY}

\section{Individual advocacy}

Self advocacy is clearly desirable if it is achievable. The successful self advocacy of children requires overcoming the cultural and institutional barriers children face in getting heard in a society in which the non-participation of children in decision making is the norm.

The voluntary sector has developed great skills in the area of supporting the self advocacy of older children and young people. In Wales, until recently, the Children's Society was the largest provider of such services, providing support to children and young people looked after by local authorities, those who had left care, child "runaways", those who came into child protection systems, and to the wider group of children in need who were receiving help and support from local authorities. These services are deliberately partisan in that they are designed to assist children and young people to say what they want to say, either by sitting alongside them to support them in doing this, or by speaking their words on their behalf. It involves a process of assisting children and young people to understand what's happening to them, helping them identify the options they have available to them and supporting them in conveying their views in what are, usually, adult dominated situations. It requires skilled staff with appropriate competencies. Empowering children and young people to protect themselves in this way provides an important safeguard in their contact with services.

Such services are not yet commonplace within the health sector, which has, in general, been slow to accommodate and integrate such initiatives into health care. It is not difficult to envisage situations in which such a service could support children in fully participating in decision making in which they may have difficulty in articulating their needs and wishes or may be in conflict with their parents and carers. Examples include: supporting the pregnant teenager in deciding how to proceed; helping a terminally ill child have control over their own dying; allowing a disabled child to feed fully into decisions around educational placement; and supporting a child in care to give fully informed consent to surgical or medical interventions.

Health providers need to learn from the experiences of local authorities and the voluntary sector in this area, and start to plan how to build these processes into core services. Whether a child is deemed Gillick competent or not, they still have a right to be heard in line with Article 12 of the UN Convention for the Rights of the Child:

"States parties shall assure to the child who is capable of forming his or her own views the right to express those views freely in all matters affecting the child, the views of the child being given due weight in accordance with the age and maturity of the child"

\section{Group advocacy}

Self advocacy at a group level is potentially a very powerful tool in needs assessment and priority setting for health services for children. There are, however, three potential problems that need addressing. These are as follows.

1 The tensions between demands and needs

Demands and needs are not the same. In addition, assessing needs requires both individual and population perspectives. A whole population perspective is unlikely to emerge from consultations with groups of children and young people, which are also unlikely to incorporate the requirements of poorly resourced stretched services charged with meeting the needs of all children.

2 The tensions between the needs of deprived versus advantaged groups It is important to avoid the "inverse noise law" of advocacy, in which the voices of most needy and marginalised children are not heard. One is minded of National Children's Bureau conferences in the mid 1990s in which children's views were presented by children of the staff of the Children's Rights Office, and professional newsletters in which contributors with very familiar surnames provide the child's view. This approach, however well meant, is unacceptable. It is always the poor and marginalised whose rights are most easily ignored or most flagrantly abused. It is no coincidence that looked after children have suffered within the care system so appallingly and for so many years. They were ignored both individually and collectively. Currently many childcare professionals in the UK are increasingly disturbed at what is happening to refugee children. If we want to build rights led, child centred, health services, asylum seekers' and travellers' children, incarcerated children, and the children of Glyn Corw, Mosside, and Easterhouse must also be allowed to share their experiences and voice their vision. Indeed they need a more powerful voice. This won't happen unless specific strategies are implemented.

There are examples of good practice in which consultation with children and young people has been fully inclusive. Children and young people were integral to the selection and appointment of the successful candidate for the post of the Children's Commissioner for Wales. The Welsh Assembly was supported in this by agencies that already had a well developed track record in supporting self advocacy for children in need (Children in Wales, Voices from Care, the Children's Society). The group sitting on the appointments committee included looked after and learning disabled children and 
was geographically and linguistically representative.

There is also plenty of convincing evidence from the Child-to-Child programme showing that children can be effective partners in health alliances and can transform their own lives. There are unfortunately few people with the required skills to support child-to-child initiatives in the UK. It is an area that ought to be developed.

3 The marginalisation of the needs of very young children

In a speech given shortly after the appointment of the Children's Commissioner, Rhodri Morgan, the Welsh First Minister, stated, "the client group was represented on the appointment committee". This was only partially true There were no specialists in early years within the appointment process with the sole remit of advocacy for young children. This was an important omission. Social disadvantage has the most impact on the very young, with long term consequences for school outcomes, employment prospects, and health. We must guard against the complacency that successful consultation with older children can provoke. Not only may the needs of the very young be ignored; if strategies to improve their situation are at odds with those to improve the situation of older children and young people, consulting only with the latter in the context of policy development could exacerbate the predicament of young children. They need advocates to do exactly what the quotation above appears to deride-say what is best for them.

\section{ADVOCACY: WHO SHOULD ADVOCATE FOR CHILDREN? Parents}

Parents advocate for their own children, and, as a group, have been very successful in improving the care of children within the NHS. Action for Sick Children started off as a parent led pressure group and played a major role in making in-patient facilities and policies more child and family centred. However, like many such groups, its voice is generally that of the more advantaged in our society.

\section{The independent sector}

Independent agencies have an important role, and a long track record, in advocating on behalf of children. Such agencies include child rights organisations, such as the National Children's Bureau, and children's organisations with specific remits, for example, the National Deaf Children's Society and the NSPCC.

\section{Child health professionals}

Child health professionals ought to have a key role as advocates for the needs of their client group within an organisation whose main focus, in policy, planning, and delivery of services, is on the adult population. Indeed paediatrics came into being largely because doctors caring for children recognised that their needs were different to those of adults. Professional advocacy is currently unfashionable in today's "consumer" focused culture. Paediatricians in particular appear to be marginalised in policy development, with management being much more influential but lacking a knowledge base. There is a need to argue for evidence based policies and planning processes for children's services, for which senior child health professionals are essential. Child health professionals have a very weak voice in Primary Care Trusts in England and their equivalents in Wales and Scotland. Their membership is heavily biased towards the needs of older people, and is reflected in their priorities. For example, one such Trust in Cardiff identified "tele-dermatology" as one of its three priorities for 2001. Children did not figure in either of the others.

Advocacy should be integrated into the core curriculum for postgraduate training in paediatrics and child health.

\section{Early years specialists}

Early years specialists are professionals with a focus on very young children. They may come from a variety of backgrounds-health, education, psychology, and sociology-but will share an in-depth knowledge of early childhood development, and the needs of this group. They are key to providing advocacy for the very young.

\section{PARTNERSHIP IN ADVOCACY}

There are many children whose socioeconomic deprivation is accompanied by other, sometimes multiple, social factors which compound their disadvantage - so called double jeopardy. Providing advocacy for these children requires a range of skills and knowledge that is hard to find in one individual or organisation. Organisations supporting marginalised groups within society, for example, Shelter, Women's Aid, Refugee Councils, may not focus on children but are potentially important partners in developing strategies to reduce health inequalities and inequities in provision. For example, the British Refugee Council worked with the RCPCH to develop superb guidelines for care of refugee children. In Cardiff child health staff have established partnership with Women's Aid organisations, which have provided invaluable insights into the lives and needs of children fleeing domestic violence, how health services are currently failing them, and how to improve access.
Black and minority ethnic children The largest group facing double jeopardy are children in poverty who are also members of minority ethnic communities. The incidence of socioeconomic deprivation is higher in these communities with, for example, over $60 \%$ of the British Pakistani and Bangladeshi communities in poverty. Children from minority ethnic communities are more likely to be disabled, to be excluded from school, and to be looked after by the local authority. They are also over represented in national inquiries into child abuse deaths. There are complex reasons for these differences that cannot be explored here, but part of the explanation is their experience of discrimination and racism.

These children are also marginalised in advocacy. Their needs are in the main poorly represented by organisations advocating on behalf of children, while the needs of children are poorly represented by organisations advocating on behalf of racial and ethnic minorities. For example, in 1998 the Affia Trust, a Black led, government funded organisation, hosted a two day conference on the health of ethnic minority populations that contained not a single item on children. Similarly textbooks by Smaje and Nazroor on ethnic minority health have focused almost exclusively on adult health. This is ironic as $33 \%$ of these communities are aged under 16, compared to $19 \%$ overall.

Partnership would enable organisations to share skills and knowledge to advocate for this group. Cardiff ABCD is an example of a partnership between a Race Equality Council (REC) and child health staff, which seeks to improve the lives of children from minority ethnic communities with disability or chronic illness. One of its roles has been that of advocacy, on behalf of individuals, families, and communities. It has raised the profile of this client group within statutory and voluntary sectors, and is valued both by the communities themselves and by policy makers. Child health providers in all parts of the UK could usefully link up with their local REC or CRE (Council for Racial Equality).

\section{CULTURAL COMPETENCE}

Working in partnership, whether with other agencies in advocacy, or with children or marginalised communities in supporting self advocacy, requires cultural competence in its broadest sense. This is essential if one is to avoid a deficit model of service provision. Without cultural competence we will fail to meet the needs of children at the most basic levels. For example, culturally competent services and practitioners are central to the success of the new Assessment Procedures for children in Need, published by the Department of Health, 
which calls for a strengths based model of partnership.

Cultural competence is currently not prioritised in undergraduate curricula, although several British medical schools, notably Birmingham and Leicester, have made progress in this area. In postgraduate paediatric training in the UK it is not included in the curriculum and, although it is an available option for residents in the USA, it is an unpopular option weakened by a strong biomedical and unidisciplinary training ethos.

\section{BUILDING ADVOCACY INTO SERVICE INFRASTRUCTURE}

Several years ago, in my then NHS Community Trust, a focus in the trust on widening access to adult mental health services led to the opening of drug and alcohol clinics in many health centres in deprived wards of the city-a laudable achievement. Unfortunately many of these clinics clashed with pre-existing paediatric speech therapy and audiology clinics serving very needy child populations and resulted in a notable increase in non-attendance. The changes were implemented with no discussion or thought as to their impact on children. Integrating impact statements into process at all levels of planning, policy, and service delivery is one way of building in advocacy into the structures. Ideally these impact statements should include children, disabled people, and marginalised groups, and operate at all levels from central government to Trust Directorates.

\section{THE THREAT OF THE MEDIA}

In the past few years there have been several programmes on terrestrial television in the UK exploring attention deficit hyperactivity disorder (ADHD). These programmes illustrate well how the media both reflect and direct societal attitudes to children. They ignored children's rights in that they were exploitive, contravened a child's right to privacy, and were certainly not in the best interests of the children involved. They provided inaccurate presentations of children with ADHD (indeed many of the cases were conduct disordered children in very disadvantaged circumstances) with a focus on these children not as in distress, but as "mad, bad, and dangerous to know".
The media are also a powerful influence of health policy. Contrast the media's response to the murder of James Bulger to that of people killed by mentally ill adults, the most high profile of which was the stabbing of Jonathan Zeto by Christopher Clunis on a London tube station. James Bulger's death was just as much a health issue as was Jonathan Zeto's. But while the media argued that inadequate community mental health services, not Christopher Clunis, were responsible for Jonathan Zeto's death, it demonised James Bulger's killers, both of whom who had experienced deprivation or abuse. The link between James Bulger's death and a lack of child mental health services was not made, although professionals working in the area of child protection recognise that the interventions available for neglected and abused children, both in terms of post abuse work and in mental health promotion, reach only a fraction of those who could benefit. This media bias was reflected in Trusts' priorities in the early 1990s. Commissioning of children's health services was investigated by the Audit Commission in 1994, which found that most health authorities were not even addressing children's services. The main priority of many was adult mental health, reflecting its high media profile at that time.

\section{CONCLUSION}

\section{Advocacy beyond the NHS}

At the end of the last century the number of children dying from burns and scalds in the homes of Merthyr Tydfil miners outnumbered the number of miners killed in accidents. The opening of the pithead head baths had a much more dramatic impact on these mortality rates than could the opening of the most well equipped burns unit imaginable. Now, as then, health services per se play a minor role in determining the state of our children's health, except in so much as the inverse care law compounds the poor health associated with poverty. Much more important are the environments in which children live-at home, in school, and in the wider world.

Important areas for advocacy are poverty, accidents, violence, supporting parents, and healthy school environments. Consider one example: cheap school furniture and the carrying of heavy loads by secondary school children are both potentially detrimental to the spine. This has been highlighted as an important health issue in other countries. Denmark earmarked monies to provide school furniture that was posturally safe. Italy highlighted the need to prevent children form carrying heavy bags of books. Neither issue has reached the public or political consciousness here although both apply. Children are required to carry loads that no employer could require of members of the workforce, who are protected under Health and Safety at Work regulations. There are no "Health and Safety at School" regulations to afford growing and physically immature young people the same protection. Why not? Why are their rights and needs overlooked? Likewise why do we have such high child death rates from abuse and pedestrian traffic accidents?

Although we must argue for better and appropriate health services for children and young people, our biggest task in advocacy is to change the reality of our children's lives. The RCPCH and associated organisations such as BACCH (British Association for Community Child Health) have already developed important partnerships both within the UK (for example, the National Children's Bureau), and internationally (for example, the American Association of Paediatrics), to develop advocacy. We need to build on these partnerships and take advantage of new potential partners in advocacy, such as the Commissioner for Children's Rights in Wales. Children's Rights Commissioners, sometimes known as Children's Ombudsmen, have been very powerful sources of advocacy in other countries, and could potentially be so here as well.

\section{ACKNOWLEDGEMENTS}

I would like to acknowledge Professor A Aynsley-Green who gave me the opportunity to present this paper at a joint meeting of the RCPCH and the National Children's Bureau, and whose idea it was to pursue its publication.

Arch Dis Child 2002;87: 175-177

\section{Author's affiliation}

E Webb, Department of Child Health, University of Wales College of Medicine, Cardiff UK.

Correspondence to: Dr E Webb, Senior Lecturer, Department of Child Health, University of Wales College of Medicine, Cardiff CF14 4XN, UK 